\title{
Preliminary Investigation of Acoustical Properties of Concrete Containing Oil Palm Shell as an Aggregate Replacement
}

\author{
$J$. Zanariah $^{1, *} H$. Zaiton ${ }^{1}, Y$. Musli Nizam ${ }^{2}, Y$. Khairulzan $^{1}, M$. Dianah $^{1}, D$. Nadirah $^{1}$, and \\ $O$. Mohd Hanifi ${ }^{3}$ \\ ${ }^{1}$ Faculty of Civil Engineering, Universiti Teknologi Malaysia, 81310 Johor Bahru, Johor, Malaysia \\ ${ }^{2}$ Faculty of Mechanical and Manufacturing Engineering, Universiti Tun Hussien Onn, 86400 Parit \\ Raja, Batu Pahat, Johor, Malaysia \\ ${ }^{3}$ Faculty of Civil and Environmental Engineering, Universiti Tun Hussien Onn, 86400 Parit Raja, \\ Batu Pahat, Johor, Malaysia
}

\begin{abstract}
Research has been so far focused extensively on mechanical properties of oil palm shell (OPS) concrete but less on sound properties. Thus, the objective of this study is to investigate whether concrete containing OPS can be applied in the field of road noise barrier. The acoustic properties of the samples were determined by using an impedance tube connected to a sound source. The noise reduction coefficient (NRC) and weighted sound absorption coefficient $\left(\alpha_{\mathrm{w}}\right)$ which is more commonly use in the road traffic noise barrier field were calculated according to BS EN ISO 11654:1997. Compressive strengths of samples were also determined by using compressive test. The results presented that the compressive strength of the OPS composites decreased as increased in w/c wit minimum of $20.44 \mathrm{~N} / \mathrm{mm}^{2}$ at 28 days for $\mathrm{w} / \mathrm{c}=0.6$ but still satisfactory for structural use. The sound absorption coefficient demonstrated that they were decreased as the w/c are higher with typical curve of two peaks at $315 \mathrm{~Hz}$ and $1000 \mathrm{~Hz}$. All samples were then can be classified as class E as $0.5<\alpha_{\mathrm{w}}<0.25$ and should be classified as $\mathrm{L}$ due to favourable deviation higher than 0.25 for $250 \mathrm{~Hz}$.
\end{abstract}

\section{Introduction}

Palm oil has made impressive and sustained growth in the global market, the average annual production of palm oil in Malaysia will reach 15.4 million tonnes. Thus large amount of wastes from palm mill such as oil palm shell has been generated. Based on the fundamental principles of waste management, the waste generated from palm oil industry should be minimise, recycle the waste or reuse as alternative. For this reason, the need for seeking new application in other industries where the oil palms shells can be recycled.

Another environmental pollution, which is becoming an important problem to human, is noise pollution. Exposure to high intensity noise would lead to hearing loss [1]. Exposure

\footnotetext{
* Corresponding author: riah_yaya@yahoo.com
} 
to lower intensity but long term such as transportation noise is generally bring the implication of various health problems such as stroke, heart disease, stress and sleeping disorder. There are many alternative mitigate noise generate from road such as by using noise barrier. Generally, noise barrier is functioning by obstructing the propagation path between the noise source and receiver. Concrete barrier is the most frequently used across Europe. Following this footstep, Malaysia has also increased the usage of concrete noise barrier in recent years.

The higher demand of concrete noise barrier will drastically reduce natural stone deposits. To tackle this problem, an alternative method or material such as recycled or waste materials, needs to be identified to minimize the decrease of natural aggregates. In the field of concrete research, the replacement of aggregate in concrete with waste is a popular topic. As a result, the oil palm shell (OPS), which are light and naturally sized was ideal for substituting aggregates in concrete construction. For example replacement of aggregate with oil palm shell (OPS) in concrete, which is suitable for lightweight concrete [2-8]. Studies by [8] found that oil palm shell was the organic aggregate which is better impact resistance compared to normal weight aggregate. Besides, OPS contain many pores and the water absorption is high compared to normal weight aggregate. Increasing voids in concrete would probably increase the porosity of the concrete [2]. Referring to AS 3600 minimum compressive strength for solid loadbearing block is $10 \mathrm{MPa}$ and for solid nonloadbearing block is $3.0 \mathrm{Mpa}$.

Thus, the aims of this research are to investigate the acoustical properties oil palm shell, which can reduce traffic noise pollution levels and to recycle an industrial waste. The objective of this study is to investigate whether concrete with OPS is possible to use for acoustic purpose such as noise barrier.

\section{Materials and methods}

\subsection{Collection and preparation of oil palm shell}

The oil palm shell was obtained from oil palm mill located at Kulai Johor, Malaysia. They were freshly discarded and were irregularly shapes. On this study, most of the shells were within the thickness $0.15-0.5 \mathrm{~mm}$ and the surface texture of shell fairly smooth for concave faces. Pre-treatment is necessary to remove dust and other impurities before used in concrete. In this research, the shells were soaked in hot salty water for about $10 \mathrm{~min}$ to remove all the impurities and to avoid microbial deterioration. Then the OPS were sundried until there is no water in shell. After that, these dried shells were sieved to remove the fibres and all the shell sizes range $5 \mathrm{~mm}$ to $10 \mathrm{~mm}$ were collected and kept in dry room condition. Fig. 1 shows the OPS after all impurities were removed.

Due to the high water absorption of OPS, pre-soaking of OPS is necessary. The shell was soaked in water for $24 \mathrm{~h}$, and then air dried in the laboratory for $48 \mathrm{~h}$ before use to ensure the shell in the saturated surface dry condition.

\subsection{Preparation of test specimen}

The proportion of OPS concrete and control concrete mixes were obtained from the trial mix by using the design of experiment (DOE) method to design the concrete with grade 25 . The oil palm shell (OPS) concrete samples using different water-cement ratio of $0.4,0.5$ and 0.6 as a matrix and were replace $50 \%$ of coarse aggregate with OPS. The specimens were combination of cement, water, fine and coarse aggregate and oil palm shell. Cement, 
aggregate and OPS was placed in the mixer and were mix until a homogenous mixture was achieved.

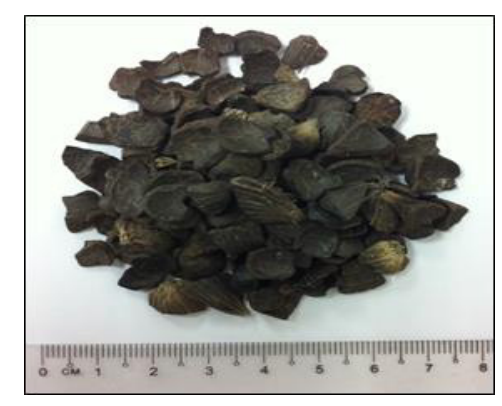

Fig. 1. OPS sizes $5-10 \mathrm{~mm}$.

Then, water was added to the mixture and re-mixed until a homogenous paste was obtained. When the mixing was completed, the slump test was carried out to measure the workability of concrete. The workability of concrete is important to describe the ease of flow in a simple index, which can reduce the void from destroying the stability of concrete [9]. All mixes of concrete should achieve a good workability, so that no segregation and bleeding occurs and improves the strength of concrete.

Then, the paste was placed in moulds of cubes $(100 \times 100 \times 100 \mathrm{~mm})$, cylinders $(98 \mathrm{~mm}$ diameter) and cubes $(50 \times 50 \times 50 \mathrm{~mm})$. The paste was compacted using vibrating table when the paste half-full in moulds and full in moulds. After $24 \mathrm{~h}$, the concrete paste was taken out from the moulds and was cured in water.

\subsection{Test methods}

\subsubsection{Compressive test}

Concrete cubes $(100 \times 100 \times 100 \mathrm{~mm})$ were tested in compression at the end of 7, 14 and 28 days by using compression machine with maximum capacity $3000 \mathrm{kN}$ with control rate $3.0 \mathrm{kN} / \mathrm{s}$. The averages of three samples were calculated to obtain the compressive strength value. Compressive strength can be calculated by using the formula:

$$
C(s)=P / A
$$

where $C s=$ compressive strength; $P=$ maximum applied load $(\mathrm{kN}) ; A=$ cross sectional area $(\mathrm{mm})$.

Before that, the dry density of the sample needs to measures. The decrease of the density will affect the compressive strength of the OPS concrete. According [10] as the dry density of concrete increased, the percentage of porosity in concrete is exponentially dropped [10]. This follows the fundamental relationship between strength of solid and porosity [9] In this study, porosity of the OPS concrete was determined by using vacuum saturated method. The sample uses for this porosity test are sized 50x50x50 mm.

\subsubsection{Impedance tube test}

To determine the acoustic properties of the samples, the sound absorption coefficient at normal incidence was determined by the transfer-function method described in EN ISO 11654-2 [11]. Transfer-function method often called the two-microphone method and the 
advantages of using this approach is that it obtains the absorption coefficient and impedance of the surface for all frequencies [12]. Thus, impedance tubes were used to measure the sound absorption of materials. Fig. 2 shows the impedance tubes for measuring the sound transmission loss consist of three parts: an upstream tube with a loud speaker, a removable test sample holder and a downstream tube with a semi-anechoic termination. The diameter of the tube used in this study is $100 \mathrm{~mm}$ and reliable frequency range is $350 \mathrm{~Hz}$ to $1500 \mathrm{~Hz}$ for low frequency. The frequency range corresponds to diameter of the tube. For high frequency, the tube with smaller diameter is used.

Basically, when the sound wave strikes a material that inserted in tube, a portion of sound wave is absorbed and other portion is reflected back. As a result, the ratio of absorbed energy to total incident energy can be determined and it called as sound absorption coefficient $(\alpha)$. In this study, three samples for each composition have been measured to ensure the value obtained more accurate.

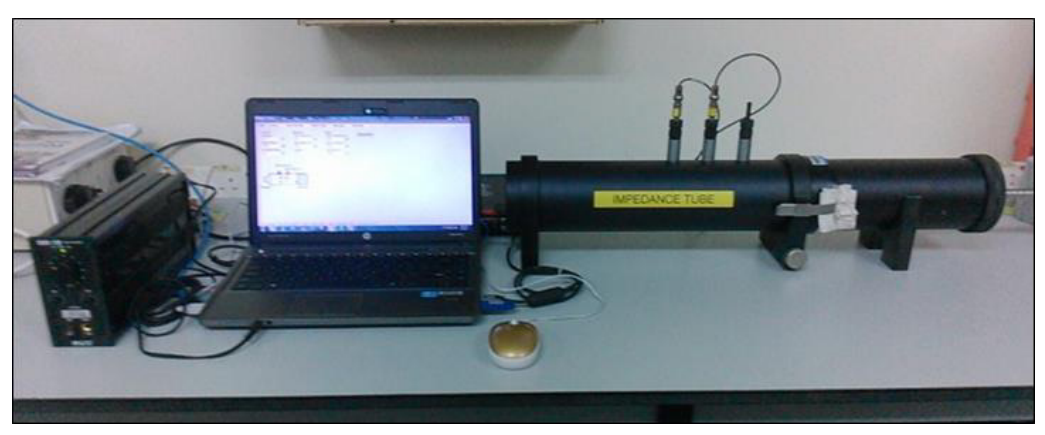

Fig. 2. Impedance tube equipment.

\subsubsection{Data analysis}

The noise reduction coefficient (NRC) was determined by calculating the arithmetic mean of the absorption coefficient at 250,500, 1000 and $2000 \mathrm{~Hz}$ (Equation 2), in order to have single numeric data of the sound absorption coefficient to make comparisons.

$$
N R C=\frac{a_{250}+a_{500}+a_{1000}+a_{2000}}{4}
$$

However, for road traffic noise barrier field, the weighted sound absorption coefficient $\left(\alpha_{\mathrm{w}}\right)$ is commonly used [12] and was calculated by referring [11]. A weighted sound coefficient $\left(\alpha_{\mathrm{w}}\right)$ is a result from comparison between the sound absorption coefficient values at standard frequencies and reference curve in accordance with ISO 11654. The $\alpha_{\mathrm{w}}$ also used to classify the sound absorption materials based on the measured absorption curves to categories from A to E.

\section{Results and discussions}

\subsection{Workability}

In this study slump test was used to determine the workability of concrete. The results obtained from slump test are presented in Table 1. Data presented in table reveals that workability gradually increased with increase water cement ratio. Water cement ratio has much effect in workability. Workability is directly proportion to water cement ratio. 
Table 1. Slump test of OPS concrete.

\begin{tabular}{|c|c|c|c|}
\hline Water/cement ratio & 0.4 & 0.5 & 0.6 \\
\hline $\mathbf{5 0} \%$ OPS & $20 \mathrm{~mm}$ & $25 \mathrm{~mm}$ & $35 \mathrm{~mm}$ \\
\hline
\end{tabular}

The measured slump values for concrete with water cement ratio 0.5 and 0.6 were $25 \mathrm{~mm}$ and $35 \mathrm{~mm}$, respectively as shown in Table. This is due to the increase the specific surface as a results increase in the quantity of OPS, requiring more water to make the mix workable. Besides, according to [4], the workability of fresh concrete influenced significantly by physical properties such as roughness, shape and texture of aggregate. The smooth surface OPS may lead to a better workability. In this study, the OPS have varies irregular shape and porous texture. The shape and surface texture of OPS control the void content and affect the water requirement of concrete. However, all the measured slumps were true slumps. Higher slump indicate higher workability of fresh concrete while lower slump indicate low workability.

\subsection{Compressive strength}

The trends of compressive strength for each sample of the same percentage of OPS with different water cement ratio increased as the curing period increased as shown in Fig. 3. The OPS concrete with water/cement ratio 0.4 attained the highest compressive strength with $38.71 \mathrm{MPa}$ within 28 days. The mix was dry and more efforts of compaction were needed during the concrete casting.

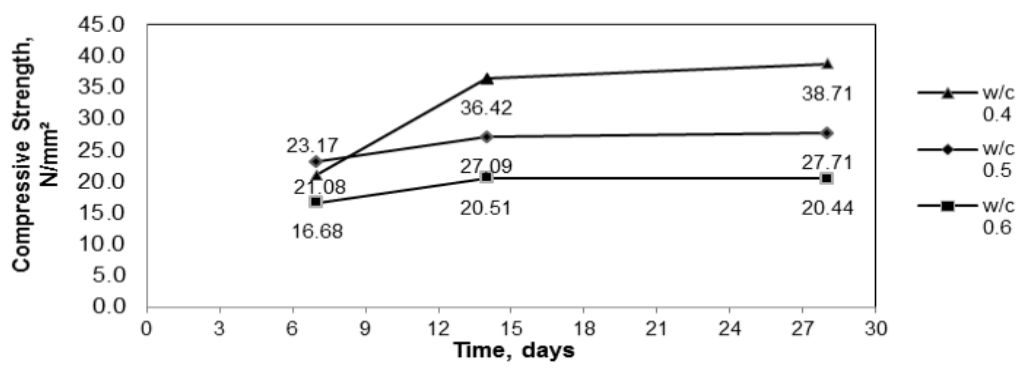

Fig. 3. Compressive strength of OPS concrete.

In contrast, the oil palm shell with highest water cement ratio has the lowest compressive strength. The excessive amount of water in the concrete mix will evaporate and thus causing void development in concrete. Based on Fig. 4 the dry density of OPS concrete decreased as the water cement ratio increased. Besides that, Fig.5 shows the porosity of the OPS concrete increased as the water cement ratio increased. That means, the void ratio in oil palm shell concrete samples reduce the strength of concrete and makes the concrete porous. Hence, the increasing w/c ratio in concrete, the samples become more porous and lighter. The compressive strength for water cement ratio 0.6 was found to be lower than the design concrete. Therefore, the most porous materials had the weakest compressive strength. 


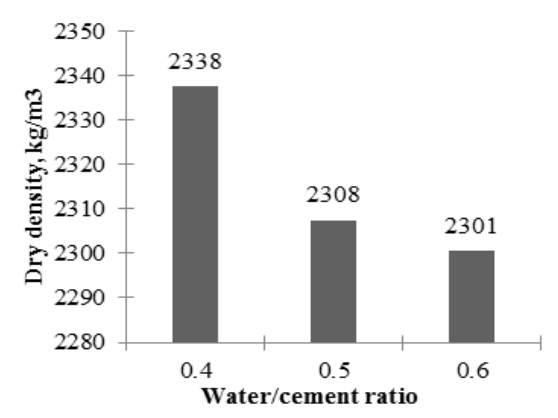

Fig. 4. Dry density versus water cement Fig. 5. Porosity of OPS concrete. ratio.

\subsection{Sound absorption coefficient}

The average the acoustic experiment results from the three samples for each w/c were plotted. Fig. 6 shows the sound absorption curves for 50\% OPS replacement in concrete with different water cement ratio of $0.4,0.5$ and 0.6 , represented in one-third octave bands. The sound absorption coefficient curves for all three different water cement ratio reach peak absorption at different frequency. The samples with water cement ratio 0.4 and $50 \%$ of OPS have the maximum sound absorption coefficient of 0.49 at $315 \mathrm{~Hz}$ (at 1st peak) and 0.26 at $1000 \mathrm{~Hz}$ (2nd peak). While the samples of w/c ratio 0.6 and $50 \%$ OPS has the lowest sound absorption coefficient at frequency 315 and $1000 \mathrm{~Hz}$, respectively for $1 \mathrm{st}$ and 2nd peak. Due to the same amount of OPS content, the density of the sample depends on the water cement ratio. Thus, water cement ratio shows the great influence on the sound absorption coefficient

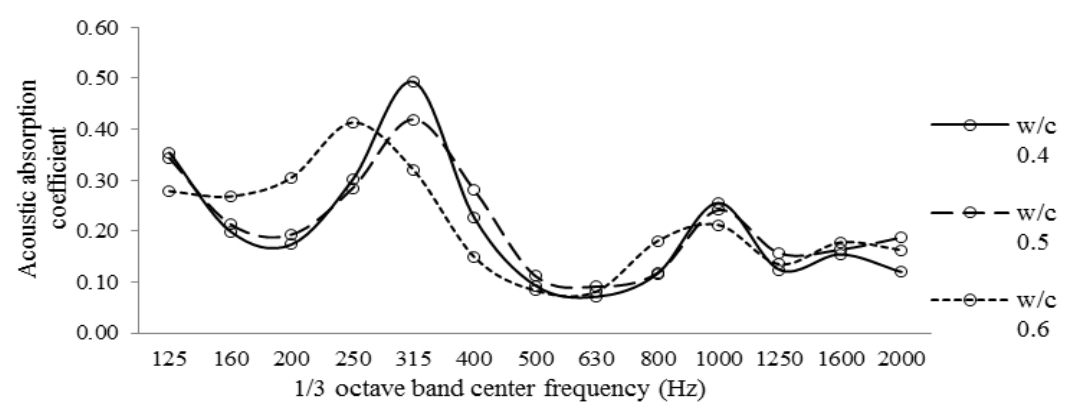

Fig. 6. Relationship between water cement ratio and sound absorption (50\% OPS).

\subsection{Noise reduction coefficient}

Noise reduction coefficient (NRC) represents a single number, which is the average value of the absorption coefficients of the samples at frequencies 250, 500, 1000 and $2000 \mathrm{~Hz}$. The NRC is the percentage of sound that a surface absorbs. Fig. 7 shows the calculated $\mathrm{NRC}$ for the three different water cement ratio with the same amount of OPS. It can be observed from this figure that NRC increased with increasing values of water cement ratio. The highest sound absorption was obtained at water cement ratio 0.6 with the value 0.22 but all samples have NRC of 0.2 . This result occurs because the higher porosity $(14.2 \%)$ compared to the other w/c as shown in Fig. 5. 


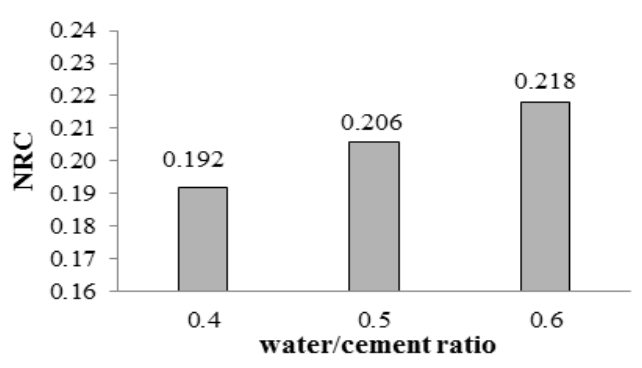

Fig. 7. Variation of NRC with water/cement ratio.

\subsection{Weighted sound absorption coefficient}

Table 2 shows the calculated value of practical sound absorption coefficient, $\alpha_{\rho}$ for all samples and the values of $\alpha_{w}$. The $\alpha_{\rho}$ is plotted against the frequencies and compared to a reference curve. The weighted sound absorption coefficient $\alpha_{w}$ is the defined as the value of the reference curve at $500 \mathrm{~Hz}$.

Table 2. $\alpha_{\mathrm{w}}$ for different water cement ratio.

\begin{tabular}{|c|c|c|c|c|c|c|c|c|c|}
\hline \multirow{2}{*}{$\begin{array}{l}\text { Absorption } \\
\text { Frequency } \\
\text { [Hz] }\end{array}$} & \multicolumn{3}{|c|}{$\mathrm{w} / \mathrm{c}=0.4$} & \multicolumn{3}{|c|}{$\mathrm{w} / \mathrm{c}=0.5$} & \multicolumn{3}{|c|}{$\mathrm{w} / \mathrm{c}=0.6$} \\
\hline & $\begin{array}{c}\alpha_{\mathrm{s}} \\
3 \mathrm{rd}\end{array}$ & $\begin{array}{c}\alpha_{\rho} \\
\text { Octave }\end{array}$ & $\alpha_{w}$ & $\begin{array}{c}\alpha_{\mathrm{s}} \\
3 \mathrm{rd}\end{array}$ & $\begin{array}{c}\alpha_{\rho} \\
\text { Octave }\end{array}$ & $\alpha_{w}$ & $\begin{array}{c}\alpha_{\mathrm{s}} \\
3 \mathrm{rd}\end{array}$ & $\begin{array}{c}\alpha_{\rho} \\
\text { Octave }\end{array}$ & $\alpha_{w}$ \\
\hline 200 & 0.17 & \multirow{3}{*}{0.30} & \multirow{9}{*}{$\begin{array}{c}0.2 \\
\text { (Class E) }\end{array}$} & 0.19 & & \multirow{9}{*}{$\begin{array}{c}0.2 \\
\text { (Class E) }\end{array}$} & 0.31 & & \multirow{9}{*}{$\begin{array}{c}0.2 \\
(\text { Class E) }\end{array}$} \\
\hline 250 & 0.30 & & & 0.28 & 0.30 & & 0.41 & 0.40 & \\
\hline 315 & 0.49 & & & 0.42 & & & 0.32 & & \\
\hline 400 & 0.23 & & & 0.28 & & & 0.15 & & \\
\hline 500 & 0.09 & 0.10 & & 0.11 & 0.20 & & 0.08 & 0.10 & \\
\hline 630 & 0.07 & & & 0.09 & & & 0.08 & & \\
\hline 800 & 0.12 & \multirow{3}{*}{0.20} & & 0.12 & \multirow{3}{*}{0.20} & & 0.18 & \multirow{3}{*}{0.20} & \\
\hline 1000 & 0.26 & & & 0.24 & & & 0.21 & & \\
\hline 1250 & 0.12 & & & 0.16 & & & 0.14 & & \\
\hline
\end{tabular}

All samples were then can be classified as class E as $0.15<\alpha_{\mathrm{w}}<0.25$ and should be classified as $\mathrm{L}$ due to favourable deviation higher than 0.25 for $259 \mathrm{~Hz}$.

\subsection{Relationship between compressive strength and NRC}

The effect of compressive strength and NRC also was investigated as a method to obtain the optimum mix design of OPS concrete. Fig. 8 shows the compressive strength of OPS concrete was decreased with increasing w/c ratio, while NRC was increased with increasing w/c ratio with the same replacement of OPS. It is found that the OPS concrete have better sound absorption due to more pores of concrete. However, the more pores in OPS concrete lead to the reduction of strength of concrete strength. Okpala (1990) [2] also found that the OPS concrete has better sound insulation with increasing w/c ratio for the same mix design. Based on Fig. 8, the optimum design was at w/c ratio 0.49. 


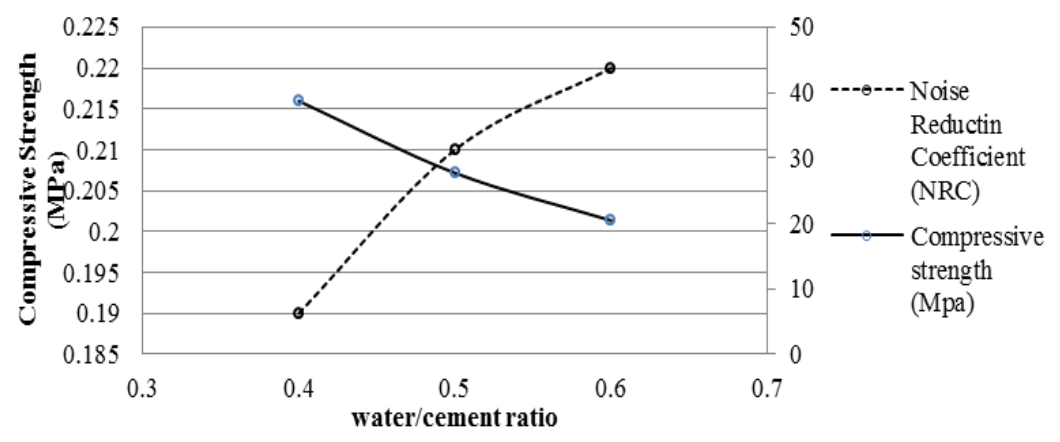

Fig. 8. Relationship w/c ratio with compressive strength and NRC values.

\section{Conclusions}

The $50 \%$ oil palm shell replacement as aggregate in concrete mixture with w/c 0.4 to 0.6 decreased the workability and strength of the concrete. Despite this, the compressive strength obtained was greater than minimum strength required by concrete block for noise barrier. Moreover, all samples can be classified E class according to BS ISO 11654 with w/c 0.6 demonstrated better sound absorption due to the higher porosity of the concrete. Therefore, the OPS concrete may be considered as new material for barrier in the future in view of reducing the problem related to the noise pollution and recycle waste.

\section{References}

1. S. Wachasunder, Int. J. Environ. Stud. 61(4), 459-470, (2004)

2. D. C Okpala, Build. Environ. 125, 29-296, (1990)

3. H. Basri, M. Mannan, M. F. Zain, Cem. Concr. Res. 29(4), 619-622, (1999)

4. M. Mannan, C. Ganapathy, Constr. Build. Mater. 16(1), 29-34, (2002)

5. D. C. L Teo, M. Mannan, V. J. Kurian, C. Ganapathy, Build. Environ. 42(7), 2614-2621, (2007)

6. P. Shafigh, M.Z. Jumaat, H. Mahmud, U. J. Alengaram, Mater. Des. 32(10), 4839-4843, (2011)

7. P. Shafigh, M.Z. Jumaat, H. Mahmud, N. Anjang, A. Hamid, Constr. Build. Mater. 27(1), 252-258, (2012)

8. U.J. Alengaram, B.A.Al Muhit, M.Z. Jumaat, Constr. Build. Mater. 38, 161-172, (2013)

9. P.M. Metha and P.J.M. Monteiro, Concrete Structure 3, (2006)

10. E.P. Kearsley, Cem. Concr. Res. 32, 233 - 239, (2002)

11. BS EN 1SO 11654:1997 Acoustics-Sound absorbers for use in buildings-Rating of sound absorption

12. J. Trevor Cox, P. D'Antonio, Acoustic Absorbers and Diffusers - Theory, Design and Application 2 (2004)

13. C.Arenas, L.F. Vilches, C. Leiva, B. Alonso-Fariñas, M. Rodríguez-Galán, Material De Construction 66 (2016) 